\title{
The Physician-Patient Relationship and Its Association with Self-Efficacy in Female Patients Managing Chronic Diseases in Riyadh, Saudi Arabia
}

\section{Reem S. Alghabiwi ${ }^{1}$, Maria Palianopoulou ${ }^{2}$, Leena Eklund Karlsson ${ }^{2 *}$}

${ }^{1}$ Health Education and Promotion Programme, College of Health and Rehabilitation Sciences, Princess Noura Bint Abdulrahman University, Riyadh, Saudi Arabia

${ }^{2}$ Department of Public Health, Unit for Health Promotion Research, University of Southern Denmark, Esbjerg, Denmark

"Corresponding author: Leena Eklund Karlsson, University of Southern Denmark, Department of Public Health, Unit for Health Promotion Research, Niels Bohrs Vej 9, 6700 Esbjerg, Denmark. Tel: +4565504158; Email: leklund@health.sdu.dk

Citation: Alghabiwi RS, Palianopoulou M, Eklund Karlsson L (2018) The Physician-Patient Relationship and Its Association with Self-Efficacy in Female Patients Managing Chronic Diseases in Riyadh, Saudi Arabia. JCommunity Med Public Health: CMPH-130. DOI: 10.29011/CMPH-130/100030

Received Date: 17 March, 2018; Accepted Date: 22 March, 2018; Published Date: 28 March, 2018

\begin{abstract}
Evidence has shown that the physician-patient relationship may affect patients in several dimensions, particularly in patients' self-efficacy in managing chronic disease. This cross-sectional study assessed the association of the perceived physicianpatient relationship on perceived self-efficacy in self-managing chronic disease in 253 female patients aged 18-55 years from six primary care clinics in Riyadh, Saudi Arabia. The data were collected using two standard questionnaires (PDRQ-9 and SEMCD) and analysis was performed using the Kruskal-Wallis test (SPSS Software). Our findings showed that overall the patients perceived the physician-patient relationship as somewhat satisfactory. Participants' self-efficacy in managing their chronic diseases was also shown to be moderate. The association between the physician-patient relationship and patient self-efficacy in self-managing chronic diseases was found to be statistically significant $(\mathrm{p}=0.047)$. The group of patients with high satisfaction with the physician-patient relationship (HSG) was found to have statistically significant higher self-efficacy compared to the group with low satisfaction (LSG) $(\mathrm{p}=0.014)$. These findings suggest that strengthening the physician-patient relationship can be an important element towards enhancing patients' self-efficacy in order to further improve the self-management and health of patients with chronic diseases in Saudi Arabia.
\end{abstract}

Keywords: Chronic Disease; Patient Satisfaction; Physician-Patient Relationship; Primary Health Care; Saudi Arabia; SelfManagement; Women Health

\section{Abbreviations}

PCP : Primary Care Physician

PDRQ-9: $\quad$ 9-item Patient-Doctor Relationship Questionnaire

PHCC : $\quad$ Primary Health Care Clinic

HSG : $\quad$ High Satisfaction with the physician-patient relationship Group

LSG : $\quad$ Low Satisfaction with the physician-patient relationship Group

MSG : $\quad$ Moderate Satisfaction with the physician-patient relationship Group

SEMCD : $\quad$ Self-Efficacy for Managing Chronic Disease scale

SPSS : $\quad$ Statistical Package for the Social Sciences

T2DM : $\quad$ Type 2 Diabetes Mellitus 


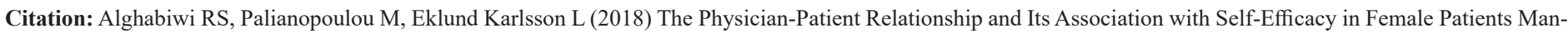
aging Chronic Diseases in Riyadh, Saudi Arabia. JCommunity Med Public Health: CMPH-130. DOI: 10.29011/CMPH-130/100030

\section{Introduction}

The prevalence of chronic diseases, such as diabetes, high blood pressure, and obesity, is growing in the Kingdom of Saudi Arabia (KSA) [1]. The increased prevalence can be seen particularly in women and adolescents, mainly due to low levels of physical activity [2], smoking [3] and unhealthy diet [4,5]. The growth of the number of patients with chronic diseases may lead to the health care system being unable to meet the needs of patients in Saudi Arabia [6]. Thus, the patients' ability to self-manage their diseases over time is becoming increasingly important for maintaining a good quality of life [7]. Self-management consists of patients monitoring their disease-related daily problems and trying to find their own solutions that they communicate to and elaborate with their doctors. Self-management consists of processes such as development of problem-solving skills, improvement of selfefficacy, and application of knowledge in real-life situations [8]. As there is no cure for chronic diseases, self-management of disease would help achieve better health, prevent other diseases and hospitalizations, and ensure efficacy of care and treatment [7,9].

Evidence shows that self-management behaviour can be strengthened by improving patient self-efficacy, e.g. through specific patient empowerment programmes [10,11]. Self-efficacy is defined as people's beliefs regarding their capabilities to influence their own behaviour, their level of motivation, their thought patterns and their emotional reactions in various life situations [12]. Bandura described self-efficacy as a mechanism that determines how people feel, think, motivate themselves, and behave. Chronic disease self-efficacy refers to the belief that one has the capabilities to undertake and complete a course of actions that are necessary to manage a given situation related to a disease [13]. Patients' self-efficacy in managing their chronic diseases can be increased by doctors who communicate effectively with their patients [14]. In addition, a positive interaction between the patient and the doctor may lead to positive health outcomes, such as increased patient satisfaction with care, better mental and physical health, and relief of symptoms, better control over disease and decreased morbidity and mortality [15-17]. The quality of the physician-patient relationship in this interaction, however, relies on the communication and interpersonal skills of the physicians [18]. However, the recent literature emphasises the active role of the patient in this relationship [19], and the evidence suggests that patients who take an active role are also more likely to engage in self-management behaviour [20]. Elements of a robust physicianpatient relationship include trust, effective communication, information-sharing between physicians and patients and empathy $[21,22]$. The physician-patient relationship is important for good quality of care. Unfortunately, the concept of the physician-patient relationship is complex and means different things to different people; thus, it is difficult to measure [23].
This study selected the physician-patient relationship for particular focus. We understood the 'physician-patient relationship' as a broad concept, the analysis of which requires multiple perspectives: the physician's accessibility, trustworthiness, readiness to help; the physician's understanding and respect for patients; the time the physician used for patients; the physician's ability to discuss health problems with the patients and to respond to their needs [24]; the physician's ability to counsel and give appropriate instructions, in order to show empathy to patients $[21,25]$ and to encourage patients to participate in decision-making regarding their care [26].

As an estimate of the effectiveness of the physicianpatient interaction, patient satisfaction regarding physician's communication has been the most recognized and widely used measure [15]. Patients' expectations and attitudes towards care are important factors, but other psychosocial factors, including pain and depression, are taken into account when defining patient satisfaction [27]. Patient satisfaction measures include how long patients have to wait to see their provider, how easily the patients can access their appointments, how quick and comprehensive is the service and what is the quality of the physician-patient relationship [28].

\section{Aim}

In Saudi Arabia (KSA), physicians communicate directly with patients mostly in Primary Health Care Clinics (PHCCs) that are the providers of acute and chronic medical care [29]. There is an ever-increasing emphasis on effective physician-patient relationships and communication in Saudi health care organizations $[30,31]$. Some of the main areas of interest of PHCCs in Saudi Arabia are treating and empowering patients with chronic diseases to strengthen their self-efficacy in self-managing their own conditions [32]. However, research regarding the effectiveness of the physician-patient relationship and its correlation with patient self-efficacy in managing chronic disease is scarce in KSA. The aim of this study was to assess the association of the physicianpatient relationship with self-estimated self-efficacy of patients managing chronic diseases; patients were selected from PHCCs in Riyadh, KSA. Effective physician-patient relationships were measured only by patient satisfaction with physician services.

\section{Methods}

\section{Settings and Participants}

A cross-sectional quantitative survey was conducted to examine the physician-patient relationship and its influence on patient self-efficacy. Six PHCCs in Riyadh, under the administration of the Ministry of Health, were randomly selected. Adult patients in the female waiting rooms of the PHCCs were asked to participate in the study. 


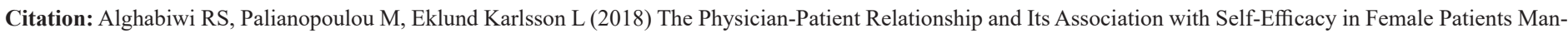
aging Chronic Diseases in Riyadh, Saudi Arabia. JCommunity Med Public Health: CMPH-130. DOI: 10.29011/CMPH-130/100030

\section{Instruments}

Data were collected using a survey consisting of demographic information and two instruments. A demographic characteristics questionnaire consisting of five items - age, nationality, level of education, type of chronic disease and number of times participants had visited the particular clinic - was developed by the investigators in order to collect sociodemographic data and data relevant to the participants' health history.

The physician-patient relationship was assessed with the 9-item Patient-Doctor Relationship Questionnaire (PDRQ-9) developed by Van der Feltz-Cornelis et al. [24]. PDRQ- 9 is a brief measure that assesses the physician-patient relationship from the patient's perspective in the primary care setting. Items were scored on a 5-point Likert scale ranging from 1 for 'not at all appropriate' to 5 for 'totally appropriate'. The mean score was calculated for each participant. Higher numbers indicate greater satisfaction with the physician-patient relationship from the patient's perspective. The scale included items regarding helpfulness (e.g. 'My PCP helps me'), trustworthiness (e.g. 'I trust my PCP'), understanding (e.g. 'My PCP understands me'), and accessibility of the doctor (e.g. 'I find my PCP easily accessible'). The internal consistency (Cronbach's alpha) of the nine scale items for the current study was 0.736 .

The Self-Efficacy for Managing Chronic Disease scale (SEMCD), developed by Lorig et al. [9] for the Stanford Patient Education Research Centre, was used to measure the self-efficacy of patients with chronic diseases. The scale consists of 6 items assessing patients' confidence in their ability to do certain activities, each item rated on a 10-point Likert scale ranging from 1 for 'not at all confident' to 10 for 'totally confident'. The mean score was calculated for each participant, with a higher score indicating higher self-efficacy. Sample items included "How confident are you that you can keep fatigue caused by your disease from interfering with the things you want to do?" and "How confident are you that you can keep the physical discomfort or pain of your disease from interfering with the things you want to do?". The internal consistency reliability (Cronbach's alpha) of this scale was 0.834 . Both instruments were translated by one of the authors from English to Arabic using translation software; the translations were then re-checked by the author, who is bilingual in English and Arabic. The Arabic version was tested on a group of five people to assure that the questions were understandable and clear.

\section{Sampling and Data Collection}

Data collection occurred between November 2015 and May 2016. A total of 277 questionnaires were distributed to patients in the waiting areas of the six PHCCs. All female adult patients who were scheduled for a clinic appointment were approached by one of the authors, with the help of the staff. After the questionnaire was explained to them, the patients were asked to participate in the study. After being screened for eligibility, the patients were given brief verbal and written information about the study. Patients aged 18 years and older, who were diagnosed with a chronic illness and who agreed to participate in the study gave informed consent and were asked to complete the self-administered survey. Questionnaires were administered by an interviewer for illiterate patients. Patients were excluded from the study if they had visited the clinic only once. A total of 253 completed questionnaires were returned, resulting in a response rate of $91 \%$.

\section{Data Analysis}

The Statistical Package Social Science (IBM SPSS Statistics), version 24.0, was used for data analyses. Descriptive statistics including the mean, median, frequencies and percentages were used to describe the general characteristics of the patients. The mean scores of the physician-patient relationship scale were divided in an ordered distribution into three groups, each containing one-third of the population. The first tertile was the lower third (low satisfaction with the physician-patient relationship (LSG)), the second textile was the middle third (moderate satisfaction with the physician-patient relationship (MSG), and the third tertile was the upper third (high satisfaction with the physician-patient relationship (HSG)). The Kruskal-Wallis test was used for the nonparametric measures as the data regarding self-efficacy were not normally distributed (Shapiro-Wilk test, $\mathrm{p}<0.05$ ). All analyses, including post hoc tests, were two-tailed, and the significance level was set at 0.05 .

\section{Ethical Considerations}

The ethical approval from the Research Ethics Committee of the Princess Noura University was obtained on 15 October 2015. A copy of the ethical clearance approval letter was provided by the researcher to the Saudi Ministry of Health in order to obtain written permission to access the clinics and distribute the questionnaires. All participants signed a written informed consent before entering the study.

\section{Results}

\section{General Characteristics of the Participants}

The sample consisted of 253 female adult patients. The general characteristics of the patients are shown in (Table 1). The age range of the participants was 18 to 55 years, with the majority being 40 to 55 years of age. The majority of the participants were Saudi nationals (80.6\%). Analysis of the educational level of the participants showed that $87 \%$ were literate, with $40 \%$ having completed high school. The type of chronic disease most reported by the patients was diabetes $(77.5 \%)$ followed by hypertension $(12.3 \%)$. More than half of the participants had visited the clinic more than three times $(56.9 \%)$, and $43.1 \%$ had visited two times. The relationship between the general characteristics of the 


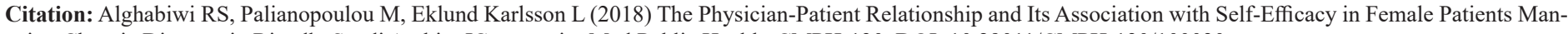
aging Chronic Diseases in Riyadh, Saudi Arabia. JCommunity Med Public Health: CMPH-130. DOI: 10.29011/CMPH-130/100030

participants by the level of satisfaction with the physician-patient relationship from the patient's perspective was not found to be statistically significant at the 0.05 level (data not shown).

\begin{tabular}{|c|c|c|}
\hline Characteristics & Category & $\begin{array}{c}\text { Total }(n=253) n \\
(\%)\end{array}$ \\
\hline \multicolumn{3}{|l|}{ Age (years) } \\
\hline & $18-29$ & $13(5.1)$ \\
\hline & $30-39$ & $33(13.0)$ \\
\hline & $40-49$ & $98(38.7)$ \\
\hline & $\geq 50$ & $109(43.1)$ \\
\hline \multicolumn{3}{|c|}{ Median $=47$, Mode $=55$, Range $=18-55$} \\
\hline \multicolumn{3}{|l|}{ Nationality } \\
\hline & Saudi & $204(80.6)$ \\
\hline & Other & $49(19.4)$ \\
\hline \multicolumn{3}{|l|}{ Educational level } \\
\hline & Illiterate & $33(13.0)$ \\
\hline & Primary & $52(20.6)$ \\
\hline & Secondary & $12(4.7)$ \\
\hline & High school & $102(40.3)$ \\
\hline & Higher education & $54(21.3)$ \\
\hline \multicolumn{3}{|l|}{$\begin{array}{c}\text { Type of chronic } \\
\text { disease }\end{array}$} \\
\hline & Diabetes & $196(77.5)$ \\
\hline & Hypertension & $31(12.3)$ \\
\hline & Both & $26(10.3)$ \\
\hline \multicolumn{3}{|l|}{ Visits to this clinic } \\
\hline & 2 times & $109(43.1)$ \\
\hline & $\geq 3$ times & $144(56.9)$ \\
\hline
\end{tabular}

Table 1: Patient characteristics.

\section{Physician-Patient Relationship}

The overall level of patient satisfaction with the physicianpatient relationship was found to be less than moderate, as was indicated by the mean score of 2.88 (95\% CI 2.80-2.96) on the ascending 1- to 5-point scale. The individual items of the PDRQ-9 scale were also characterized as relatively moderate by the participants, with the mean scores ranging from 2.81 (95\% CI 2.672.95 ) to 2.94 (95\% CI 2.80-3.09). The 'I trust my PCP' item received the lowest score, and the 'My PCP and I agreed on the nature of my medical symptoms' item received the highest score (Table 2).

\begin{tabular}{|c|c|}
\hline PDRQ-9 Items & $\begin{array}{c}\text { Mean satisfaction } \\
\text { (95\% CI) }\end{array}$ \\
\hline My PCP helps me & $2.84(2.68-3.00)$ \\
\hline My PCP has enough time for me & $2.86(2.72-3.00)$ \\
\hline I trust my PCP & $2.81(2.67-2.95)$ \\
\hline My PCP understands me & $2.88(2.74-3.02)$ \\
\hline My PCP is dedicated to help me & $2.89(2.74-3.03)$ \\
\hline My PCP and I agree on the nature of my \\
medical symptoms & $2.94(2.80-3.09)$ \\
\hline I can talk to my PCP & $2.91(2.75-3.06)$ \\
\hline I feel content with my PCP's treatment & $2.91(2.76-3.06)$ \\
\hline I find my PCP easily accessible & $2.90(2.76-3.04)$ \\
\hline Overall mean satisfaction score & $\mathbf{2 . 8 8}(\mathbf{2 . 8 0 - 2 . 9 6 )}$ \\
\hline
\end{tabular}

Table 2: Patient satisfaction with the physician-patient relationship as measured with the PDRQ-9 questionnaire.

\section{Self-Efficacy}

The median of the score for the self-efficacy scale was 6.5 on the ascending 1 to 10 scale (Table 3 ). The values of the median for the individual components of the six-item scale ranged from 7.0 to 9.0 , with the highest score being for the item regarding the patients' confidence to do other things than just taking medication to reduce how much their illness affects their everyday life 


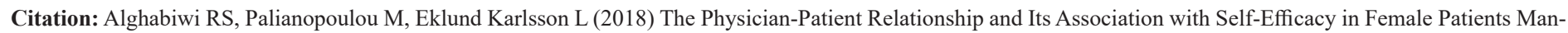
aging Chronic Diseases in Riyadh, Saudi Arabia. JCommunity Med Public Health: CMPH-130. DOI: 10.29011/CMPH-130/100030

\begin{tabular}{|c|c|c|c|c|c|c|}
\hline & $\begin{array}{l}\text { Total }(n=253) \\
\text { Median }\end{array}$ & $\begin{array}{l}\text { LSG }(\mathbf{n}=77) \\
\text { Median }\end{array}$ & $\begin{array}{l}\text { MSG }(n=94) \\
\text { Median }\end{array}$ & $\begin{array}{l}\text { HSG }(\mathrm{n}=82) \\
\text { Median }\end{array}$ & P value & Post hoc comparison \\
\hline $\begin{array}{l}\text { Self-efficacy (range 1-10)( } \uparrow \\
\text { more self-efficacy) }\end{array}$ & 6.5 & 5.5 & 6.42 & 6.92 & $0.047^{*}$ & $\begin{array}{l}a<c, p=0.014^{*} \\
b<c, p=0.429 \\
a<b, p=0.095\end{array}$ \\
\hline Fatigue (1-10) & 7 & 5 & 8 & 7 & $0.004^{*}$ & $\begin{array}{c}\mathrm{a}<\mathrm{c}, \mathrm{p}=0.034^{*} \\
\mathrm{~b}<\mathrm{c}, \mathrm{p}=0.242 \\
\mathrm{a}<\mathrm{b}, \mathrm{p}=0.001^{*} *\end{array}$ \\
\hline $\begin{array}{l}\text { Physical discomfort or pain } \\
\qquad(1-10)\end{array}$ & 7 & 5 & 7 & 7 & 0.395 & \\
\hline Emotional distress (1-10) & 8 & 5 & 8 & 8 & 0.178 & \\
\hline $\begin{array}{c}\text { Other symptoms or health } \\
\text { problems }(1-10)\end{array}$ & 7 & 5 & 7 & 7 & 0.09 & \\
\hline $\begin{array}{l}\text { Different tasks \& activities } \\
\text { needed to manage (1-10) }\end{array}$ & 8 & 7 & 9 & 9 & 0.056 & $\begin{array}{c}\mathrm{a}<\mathrm{c}, \mathrm{p}=0.016^{*} \\
\mathrm{a}<\mathrm{b}, \mathrm{p}=0.120\end{array}$ \\
\hline $\begin{array}{l}\text { Other than just taking } \\
\text { medication }(1-10)\end{array}$ & 9 & 9 & 8 & 9 & 0.208 & \\
\hline \multicolumn{7}{|c|}{$* \mathrm{p}<0.05, * * \mathrm{p} \leq 0.001$} \\
\hline
\end{tabular}

Table 3: Self-efficacy by level of satisfaction with the physician-patient relationship.

\section{Self-Efficacy by Level of Satisfaction with Physician- Patient Relationship}

Group differences in self-efficacy by the level of satisfaction with the physician-patient relationship are summarized in Table 3 . There were statistically significant differences in self-efficacy $(\mathrm{p}=0.047)$. The post hoc analysis showed that the HSG patients had higher self-efficacy than did the LSG patients $(\mathrm{p}=0.014)$.

Patients' confidence to keep the fatigue caused by their chronic diseases from interfering with the things they want to do was found to be significantly different depending on the level of satisfaction with the physician-patient relationship $(p=0.004)$. LSG patients were found to be less confident in their ability to manage fatigue than were MSG $(p=0.001)$ and HSG patients $(p=0.034)$. LSG patients were also less confident in their ability to manage with different tasks and activities needed to reduce their need to see a doctor than were HSG patients $(\mathrm{p}=0.016)$. No statistically significant differences were found for the patients' confidence in their ability to manage other activities related to their chronic diseases among the three groups (Table 3 ).

\section{Discussion}

We examined the physician-patient relationship and patients' perceived self-efficacy to manage chronic illness in the Saudi context. Our findings show that patients' perceived self-efficacy is significantly associated with the patient's level of satisfaction with the physician-patient relationship. Participants with higher satisfaction with the relationship had a stronger sense of selfefficacy in managing their chronic illnesses $(\mathrm{p}=0.047)$. This finding is supported by previous studies that proposed that physicianpatient relationships can be an essential element of patient selfefficacy $[14,33]$.

There is a general consensus that the physician-patient relationship is of great significance for providing and receiving excellent care, for the healing process and for improved health outcomes [34]. In our study, patient satisfaction with the physicianpatient relationship was found to be less than ideal, with a 2.88 (95\% CI 2.80-2.96) mean score on the 1 to 5 ascending point scale. This finding is in accordance with the findings of a previous study that focused on the satisfaction of patients with physicians' services in Saudi Arabia; this previous study showed that patients' satisfaction with physicians' communication skills, an important aspect of the physician-patient relationship, was considered to be low (2.71 in 1-5 scale), even though it was evaluated better compared to the physicians' professional skills and satisfying patients' requests [35].

Furthermore, analysis of the individual components of the instrument used in our study showed that trustworthiness was the item that received the lowest score $(2.81$ with $95 \%$ CI 2.67 $2.95)$; agreement with the physician on the nature of the medical symptoms received the highest score (2.94 with 95\% CI 2.80-3.09), 


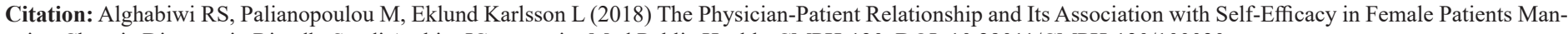
aging Chronic Diseases in Riyadh, Saudi Arabia. JCommunity Med Public Health: CMPH-130. DOI: 10.29011/CMPH-130/100030

though there were only minor variations in the item scores. Trust is considered to play an essential role in the effectiveness of the physician-patient relationship [36], and studies have previously shown that patients who trust their physicians have enhanced selfefficacy and better health outcomes [37].

Similarly, the findings of our study show that patients perceived that they had moderately low self-efficacy to manage their chronic illnesses, with a score of 6.5 on the 1 to 10 ascending point scale. This finding is consistent with the results of the study conducted by AL Abode et al [32] among patients with type 2 diabetes mellitus (T2DM), in which patients' total self-efficacy to manage their illness rated 6.97 on a scale ranging from 0 to 10 . Many studies have previously shown that patients' self-efficacy to manage their chronic illnesses is a positive and significant mediator of self-management behaviour. Patients with higher levels of selfefficacy have been found to be more compliant with prescribed medication, to perform more regular exercise and to have better health outcomes in general $[9,38,39]$. Adherence to self-care in patients with chronic diseases can lead to decreased mortality and disability, improved quality of life and reduced health care costs [9,40-42]. For this reason, countries such as Germany and the USA have recognized patients' self-efficacy in managing their chronic illnesses as an essential element of chronic care [13]. In Saudi Arabia, recent studies showed that the total self-efficacy score can significantly predict self-care behaviours among patients with diabetes and that individuals with T2DM who reported higher levels of self-efficacy also had better self-management of their disease, including behaviours related to diet, exercise, medication, and blood-glucose monitoring $[32,43]$.

Some limitations to our study should be noted. First, the study was limited to only female patients, even though the study problem is not related particularly to gender. This was because access to PHCCs was given only for female patients due to ethical issues. This also resulted in a small sample size that may have affected the findings of the study. Future studies will need to be performed in a target population that includes both genders in order to allow for the generalization of the study findings. Second limitation is connected with the illiteracy of some of the participants $(13 \%)$. In these cases the principal researcher conveyed the informants' answers. This might have caused a social desirability bias that should be taken into account in the results.

\section{Conclusion}

This study is one of the few to study the physician-patient relationship and its influence on patients' perceived self-efficacy in managing chronic illness. The findings suggested that the physician-patient relationship is an important factor that can affect patient self-efficacy in managing chronic diseases. These findings, in conjunction with the results of other studies, which also found a positive association between patient self-efficacy and selfmanagement, suggest that the physician-patient relationship can be important for improving patient self-management behaviours and improving the health of patients with chronic diseases in the Saudi context by enhancing patients' self-efficacy. This knowledge could be used by policy-makers who make decisions regarding medical education and the structure of health care services.

\section{Acknowledgements}

We would like to thank the Saudi Ministry of Health for helping us to obtain approval for this study for the collection of data.

\section{Conflicts of interest}

The authors have no conflicts of interest to declare.

\section{References}

1. GBD, Eastern Mediterranean Region Diabetes, CKD Collaborators, Mokdad AH (2017) Diabetes mellitus and chronic kidney disease in the Eastern Mediterranean Region: findings from the Global Burden of Disease 2015 study. Int J Public Health: 1-10.

2. El Bcheraoui C, Tuffaha M, Daoud F, Kravitz H, Al Mazroa MA, et al. (2016) On your mark, get set, go: levels of physical activity in the Kingdom of Saudi Arabia, 2013. J Phys Act Health 13: 231-238.

3. Moradi-Lakeh M, El Bcheraoui C, Tuffaha M, Daoud F, Al Saeedi M, et al. (2016) The health of Saudi youths: current challenges and future opportunities. BMC Family Pract 17: 26.

4. Al-Kutbe R, Payne A, de Looy A, Rees GA (2017) A comparison of nutritional intake and daily physical activity of girls aged 8-11 years old in Makkah, Saudi Arabia according to weight status. BMC Public Health 17: 592.

5. Rahim HF, Sibai A, Khader Y, Hwalla N, Fadhil I, et al. (2014) Noncommunicable diseases in the Arab world. Lancet 383: 356-367.

6. World Health Organization (2014) Noncommunicable diseases country profiles 2014, WHO, Geneva.

7. Holman H, Lorig K (2004) Patient self-management: a key to effectiveness and efficiency in care of chronic disease. Public Health Rep 119: 239-243.

8. Coleman MT, Newton KS (2005) Supporting self-management in patients with chronic illness. Am FamPhysician 72: 1503-1510.

9. Lorig KR, Sobel DS, Stewart AL, Brown Jr BW, Bandura A, et al. (1999) Evidence suggesting that a chronic disease self-management program can improve health status while reducing hospitalization: a randomized trial. Medical Care 37: 5-14.

10. Farrell K, Wicks MN, Martin JC (2004) chronic disease self-management improved with enhanced self-efficacy. Clin Nurs Res 13: 289308

11. Weng LC, Dai YT, Huang HL, Chiang YJ (2010) Self-efficacy, self-care behaviours and quality of life of kidney transplant recipients. J Adv Nurs 66: 828-838.

12. Bandura A (1977) Self-efficacy: toward a unifying theory of behavioral 
Citation: Alghabiwi RS, Palianopoulou M, Eklund Karlsson L (2018) The Physician-Patient Relationship and Its Association with Self-Efficacy in Female Patients Managing Chronic Diseases in Riyadh, Saudi Arabia. JCommunity Med Public Health: CMPH-130. DOI: 10.29011/CMPH-130/100030

change. Psychol Rev 84: 191-215.

13. Bodenheimer T, Lorig K, Holman H, Grumbach K (2002) Patient selfmanagement of chronic disease in primary care. JAMA 288: 24692475 .

14. Zachariae R, Pedersen CG, Jensen AB, Ehrnrooth E, Rossen PB, et al. (2003) Association of perceived physician communication style with patient satisfaction, distress, cancer-related self-efficacy, and perceived control over the disease. Br J Cancer 88: 658-665.

15. Kaplan SH, Greenfield S, Ware JE Jr. (1989) Assessing the effects of physician-patient interactions on the outcomes of chronic disease. Med Care 27: S110-127.

16. Heisler M, Bouknight RR, Hayward RA, Smith DM, Kerr EA (2002) The relative importance of physician communication, participatory decision making, and patient understanding in diabetes self-management. $J$ Gen Intern Med 17: 243-252.

17. Matusitz J, Spear J (2014) Effective doctor-patient communication: an updated examination. Social Work Public Health 29: 252-266.

18. Ha JF, Longnecker N (2010) Doctor-patient communication: a review. Ochsner J 10: 38-43.

19. Alexander JA, Hearld LR, Mittler JN, Harvey J (2012) Patient-physician role relationships and patient activation among individuals with chronic illness. Health Serv Res 47: 1201-1223.

20. Hibbard JH, Mahoney ER, Stock R, Tusler M (2007) Do increases in patient activation result in improved self-management behaviors? Health Serv Res 42: 1443-1463.

21. Larson EB, Yao X (2005) Clinical empathy as emotional labor in the patient-physician relationship. JAMA 293: 1100-1106.

22. Hoff T, Collinson GE (2017) How do we talk about the physician-patient relationship? What the nonempirical literature tells us. Medical Care Res Rev 74: 251-285.

23. Ridd M, Shaw A, Lewis G, Salisbury C (2009) The patient-doctor relationship: a synthesis of the qualitative literature on patients' perspectives. Br J Gen Pract 59: e116-e133.

24. Van der Feltz-Cornelis CM, Van Oppen P, Van Marwijk HW, De Beurs E, Van Dyck R (2004) A patient-doctor relationship questionnaire (PDRQ-9) in primary care: development and psychometric evaluation. Gen Hosp Psychiatr 26: 115-120.

25. Duffy FD, Gordon GH, Whelan G, Cole-Kelly K, Frankel R, et al. (2004) Assessing competence in communication and interpersonal skills: the Kalamazoo II report. Acad Med 79: 495-507.

26. Christianson J, Warrick LH, Finch M (2012) Physician communication with patients: research findings and challenges, University of Michigan Press, Ann Arbor.

27. Morris BJ, Jahangir AA, Sethi MK (2013) Patient satisfaction: an emerging health policy issue. AAOS Now 7: 29.

28. Almoajel A, Fetohi E, Alshamrani A (2014) Patient satisfaction with primary health care in Jubail City, Saudi Arabia. World J Med Sci 11:
255-264.

29. Khaliq AA (2011) The Saudi health care system: a view from the minaret. World Health Pop 13: 52-64.

30. Alofisan T, Al-Alaiyan S, Al-Abdulsalam M, Siddiqui K, Hussain IB, et al. (2016) Communication skills in pediatric training program: national-based survey of residents' perspectives in Saudi Arabia. J Family Community Med 23: 43-47.

31. Elzubier AG (2002) Doctor-patient communication: a skill needed in saudi arabia. J Family Community Med 9: 51-56.

32. Aboudi IS, Hassali MA, Shafie AA, Saleem F (2016) Self-efficacy, selfcare behaviours and glycaemic control in type 2 diabetic patients in Riyadh, Saudi Arabia. J Public Health 24: 281-290.

33. Ohya $Y$, Williams H, Steptoe A, Saito H, likura $Y$, et al. (2001) Psychosocial factors and adherence to treatment advice in childhood atopic dermatitis. Journal of investigative dermatology 117: 852-857.

34. Hopkins $\mathrm{J}$ and American Healthways (2004) Defining the patientphysician relationship for the 21st century. Disease Management 7: $161-179$.

35. Saeed AA, Mohammed BA, MagzoubME, Al-Doghaither AH. (2001) Satisfaction and correlates of patients' satisfaction with physicians' services in primary health care centers. Saudi Medical Journal 22: 262-267.

36. Brennan N, Barnes R, Calnan M, Corrigan O, Dieppe P, et al. (2013) Trust in the health-care provider-patient relationship: a systematic mapping review of the evidence base. International Journal for Quality in Health Care 25: 682-688.

37. Lee Y-Y, Lin JL. (2009) The effects of trust in physician on self-efficacy, adherence and diabetes outcomes. Social Science \& Medicine 68: 1060-1068.

38. Yoo H, Kim CJ, Jang Y, You MA (2011) Self-efficacy associated with self-management behaviours and health status of South Koreans with chronic diseases. International Journal of Nursing Practice 17: 599606.

39. Lorig KR, Ritter P, Stewart AL, Sobel DS, Brown BW Jr, et al. (2001) Chronic disease self-management program: 2-year health status and health care utilization outcomes. Medical Care 39: 1217-1223.

40. Horwitz RI, Horwitz SM (1993) Adherence to treatment and health outcomes. Archives of Internal Medicine 153: 1863-1868.

41. Horwitz RI, Viscoli CM, Berkman L, Donaldson RM, Horwitz SM, et al. (1990) Treatment adherence and risk of death after a myocardial infarction. The Lancet 336: 542-545.

42. Gallagher EJ and Horwitz RI. (1993) Myocardial Infarction in Women. JAMA 270: 742-744.

43. Albargawi M, Snethen J, Gannass AA, Kelber S (2016) Perception of persons with type 2 diabetes mellitus in Saudi Arabia. International Journal of Nursing Sciences 3: 39-44. 